\title{
Herbal Remedies in Periodontics
}

\author{
Dhalkari Chandulal' ${ }^{1}$, Wagatkar J ayshri², Ingle Kantilal ${ }^{3}$
}

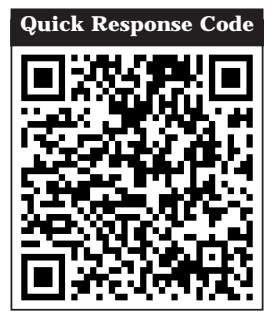

doi : 10.5866/2015.7.10255

${ }^{1}$ Associate Professor

${ }^{2} \& 3$ Senior Resident

Department of Periodontology

Government Dental College,

Aurangabad

\section{Article Info:}

Received: October 9, 2015

Review Completed: November 10, 2015

Accepted: December 11, 2015

Available Online: March, 2016 (www.nacd.in)

(c) NAD, 2015 - All rights reserved

\section{Email for correspondence:}

dr.jayshriw@yahoo.com

\begin{abstract}
:
Dental diseases if left unchecked can lead to major health problems. On the other side, periodontal diseases are recognized as a major public health problem throughout the world and are the most common cause of tooth loss in adults. Plant products are recently introduced herbal formulations that are more beneficial than the conventional therapies. There are number of traditional herbal remedies for the treatment and management of diseases related to teeth, gum and oral hygiene. The aim of the present article is to present overall view of the current strategies adopted for the formulation and application of traditional herbal remedies. The present article summarizes the current data on the effect of natural herbs on management of various periodontal diseases together with their biological activities.
\end{abstract}

Key words: Plant products, gingivitis, periodontitis, microorganisms

\section{Introduction}

Gingivitis is the inflammation of the gingiva. Plaque is a requirement for the development of gingivitis. ${ }^{1}$ Periodontitis is a polymicrobial disease in which disease expression involves intricate interactions of the plaque biofilm with the host inflammatory response and subsequent alterations in bone and connective tissue metabolism. ${ }^{2}$ Mechanical plaque control methods are efficient in maintaining adequatelevels of oral hygiene, studies have shown that patient compliance in following these methods are not adequate in a large population. ${ }^{3}$ In order to overcome the shortcomings of mechanical plaque control methods, various chemotherapeutic agents have been employed.

Herbs have various bioactive components which possess enormous medicinal value with least side effects. ${ }^{4}$ Synthetic antimicrobial agents and antibiotics are known to cause antimicrobial resistance, emergence of previously uncommon infections probably due to the inappropriate or widespread overuse of antimicrobials. Natural phytochemicals have proven to be good alternatives to such synthetic agents. ${ }^{5}$ Various studies have proven to show excellent medicinal properties of different herbal products in various medical and dental diseases. This review list outs various herbal products, their medicinal properties and their uses 
in the field of periodontics.

\section{Punica granatum (Pomegranate)}

Investigators noted that pomegranate's active components, including polyphenolic flavonoids are believed to prevent gingivitis through a number of mechanisms including reduction of oxidative stress in the oral cavity, direct antioxidant activity; antiinflammatory effects; antibacterial activity; and direct removal of plaquefrom the teeth. ${ }^{6-9}$

\section{Green tea}

Polyphenols found in tea are mostly flavonoids and catechins. ${ }^{10}$ Green tea catechin showed a bactericidal effect against black-pigmented, Gram negative anaerobic rods, Porphyromonas gingivalis and Prevotella species, and the combined use of mechanical treatment and the application of green tea catechin using a slow-release local delivery system was effective in improving the periodontal status. ${ }^{11}$

\section{Azadirachata indica (Neem)}

Neem shows antiulcer, anti-inflammatory, antifungal, antibacterial, anti-viral, anti-carcinogenic, antiarrhythmic, antiviral, antioxidant, antidiabetic activity. ${ }^{12}$ In a clinical study, 50 patients with confirmed gingivitis were sel ected, 40 showed severe bleeding and pustular discharges from the gums. After just three weeks of brushing twice a day with paste including neem leaf extracts, eight out of ten patients showed significant improvement. The patients also showed a reduction in bacterial populations and elimination of halitosis with noside effects. ${ }^{13}$

\section{Curcuma longa (Turmeric)}

Turmeric has anti-microbial, anti-oxidant, antiinflammatory astringent, anti-septic and analgesic properties. ${ }^{14} \mathrm{~A}$ study concluded that chlorhexidine gluconate as well as turmeric mouthwash can be effectively used as an adjunct to mechanical plaque control methods in prevention of plaque and gingivitis. Reduction in total microbial count was observed in both the groups. It is reported that the local drug delivery system containing $2 \%$ whole turmeric gel can be used as an adjunct to scaling and root planing. ${ }^{15}$

\section{Aloe barbadensis (Aloe vera)}

The aloe leaves contains enzymes, vitamins, minerals, salicylic acids, sugars, lignin, saponins, and amino acids. ${ }^{16}$ Various medicinal properties of Aloe vera include positive effects on wound-healing, anti-viral property, anti-tumor effect, antiinflammatory effects, anti-bacterial property, antifungal property, anti-oxidant property and immunomodulating effects. ${ }^{17}$ I $\mathrm{n}$ a clinical study al oe vera mouth rinse showed significant reduction of gingivitis and accumulation of plaque. ${ }^{18}$

\section{Acacia catechu Wild (AC)}

The extracts of AC have been reported to have various pharmacological effects like antipyretic, antiinflammatory, anti diarrhoeal, hypoglycaemic, hepatoprotective, antioxidant and antimicrobial activities. ${ }^{19,20}$ The powders of menthol and camphor were used as a flavouring agent. A clinical study on this dentifrice herbal tooth powder reported $87-95 \%$, $70-72 \%$ and $80-95 \%$ reductions in plaque, gingivitis and dental calculus respectively, about 15 days of treatment. $^{21}$

\section{Tulsi (Ocimum sanctum)}

Tulsi contains Vitamin A and C, calcium, zinc and iron. It also has chlorophyll and many other phytonutrients with several medicinal properties like expectorant, analgesic, anticancer, antiasthmatic, antiemetic, diaphoretic, antidiabetic, antifertility, hepatoprotective, hypotensive, hypolipidimic and antistress. Tulsi has also been used in treatment of fever, bronchitis, arthritis, convulsions etc. ${ }^{22}$ Its anti-inflammatory property makes it a suitable remedy for gingivitis and periodontitis, and it can be used for massaging the gingiva in these conditions. ${ }^{23}$

\section{Psidium guajava (Guava)}

The leaves of guava contain an essential oil rich in cineol, tannins, triterpenes, flavonoids, resin, eugenol, malic acid, fat, cellulose, chlorophyll, mineral salts, and a number of other fixed substances. ${ }^{24}$ The active flavonoid compound gua $\bullet$ averin has high potential antiplaque activity by inhibiting the growth of S.mutans and $\mathrm{S}$. aureus in a study carried out by disc diffusion method. 25,26 


\section{Salvadora persica (Meswak)}

Benzyl isothiocyanate, a major component of Salvadora persica, exhibited bactericidal effect against oral pathogens involved in periodontal disease. ${ }^{27}$ It is known to have anti-bacterial, antifungal, anti-plaque and anti- caries activity. ${ }^{28} \mathrm{Al}$ L afi and Ababneh reported that the use of miswak inhibits the formation of dental plaque chemically and also exerts antimicrobial effect against many mi croorganisms. ${ }^{29}$

\section{Cymbopogon Citratus (Lemon grass)}

The active ingredients present in this grass are Citronellol Geraniol which is responsiblefor its antibacterial, astringent, anti-fungal, anti-oxidant, antiseptic, anti-inflammatory properties. ${ }^{30}$ I $\mathrm{n}$ an in-vitro study it has been demonstrated that the essential oil in lemon grass has significant anti-microbial potential against oral microorganisms S.mutans, P.intermedia and P. gingivalis. ${ }^{31}$

\section{Allium sativum (Garlic)}

Allicin, one of the chief phytochemical components has a variety of antimicrobial activities against a wide range of Gram-negative and Gram positive bacteria including Klebsiella, pneumonia, Escherichia, Lactobacilli, Helicobacter pylori, Pseudomonas aeruginosa and Mycobacterium tuberculosis and anti-fungal activity, particularly against Candida al bicans, antiparasitic activity and antiviral activity. ${ }^{32}$

\section{E ucalyptus globulus (E ucalyptus)}

Studies by Nagata et al concluded that eucalyptus extract chewing gum may promote periodontal health by having a meaningful effect on plaque, gingivitis, and bleeding on probing indices in human clinical trials. ${ }^{33}$ The antibacterial activity of eucalyptus extract against several periodontopathic bacteria including $P$. gingivalis and $\mathrm{P}$. intermedia has been documented. ${ }^{34}$

\section{Mango (Magnifera indica)}

Mango leaf contains ascorbic and phenolic acids which are known to possess antibacterial properties. Studies have shown that mango leaves (magnifera indica) possess antibacterial properties against anaerobic dental microflora such as P. intermedia and $P$. gingivalis and can effectively be used as adjunct for maintenance of oral hygiene. ${ }^{35}$

\section{Conclusion}

Pharmacol ogically active phytochemicals useful for the prevention, treatment and maintenance of periodontal diseases have been widely acknowledged. Over the last decade, herbal and ayurvedic drugs have become a subject of world importance, with both medicinal and economic implications. Use of herbal extracts in the form of dentifrice, medicated gel, local drug del ivery systems proved to be efficient in preventing and treating periodontal disease. Hence in this review a brief explanation of pharmacologically active herbal plants are found to be useful in the prevention, treatment and maintenance of various dental diseases.

\section{References}

1. Informational Paper: The pathogenesis of periodontal diseases. J Periodontol 1999; 70:45070.

2. Kornman KS. Mapping the pathogenesis of periodontitis: A New Look. J Periodontol 2008; 79:15608.

3. Somu CA, Ravindra S, Ajith S, Ahmed MG. Efficacy of a herbal extract gel in the treatment of gingivitis: A clinical study. J Ayurveda Integr Med 2012; 3:8590.

4. Sangeetha J, Vijayalakshmi K. Antimicrobial activity of rind extracts of Punica granatum Linn. The Bioscan 2011; 6:11924.

5. Abdollahzdeh $\mathrm{SH}$, Mashouf $\mathrm{R}$, Mortazavi $\mathrm{H}$, Moghaddam M, Roozbahani N, Vahedi M. Antibacterial and Antifungal activities of Punica granatum Peel extracts against Oral Pathogens. J Dent (Tehran) 2011; 8:16.

6. Reddy PD, Satyanarayana T, Purushothaman M, Local Drug Delivery of Herbs for Treatment of Periodontitis. J Innov Trends Pharma Sci 2010; 1:245-251.

7. Piramal SA, J athar SR, Sirwani RP, Malhotra P. WO2008001325, 2008.

8. De Oliveira RR, Schwartz-Filho HO, Novaes AB J r, Taba $M$ J $r$, Antimicrobial photodynamic therapy in the nonsurgical treatment of aggressive periodontitis: a preliminary randomized controlled clinical study. J Periodontol 2007; 78:965-973. 
9. Morris AJ, Steele J, and White DA, The oral cleanliness and periodontal health of UK adults in 1998. British Dent J 2001; 191:186-192.

10. Sumpio BE, Cordova AC, Berke- Schlessel DW, Qin F, Chen QH (2006). Green tea, the "Asian Paradox", and cardiovascular disease. J Am Coll Surg 202:813-820.

11. Hirasawa M, Takada K, Makimura M, Otake S. Improvement of periodontal status by green tea catechin using a local delivery system: A clinical pilot study. J Periodont Res. 2002; 37:433-438.

12. Biswas K Chattopadhyay I, Banerjee R.K, Bandyopadhyay $U$. Biological activities and medicinal properties of Neem (A. Indica). Current science 2002; 82(11):1336-1345.

13. http://www.neemamerica.com/research.asp.

14. Lee KH, Kim BS, Keum KS, Yu HH, Kim YH, Chang BS, et al. Essential oil of Curcuma longa inhibits streptoccocus mutans biofilm formation. J Food Sci 2011; 76(9):226-230.

15. Behal R, Mali MA, Gilda SS, Paradkar AR, Evaluation of local drug delivery system containing $2 \%$ whole turmeric gel used as an adjunct to scaling and root planning in chronic periodontitis: A clinical and microbiological study, J Indian Soc Periodontol 2011; 15:35-38.

16. Hamman J H. Composition and applications of Aloe vera gel. Molecules 2008; 13(8).

17. Lee SS, Zhang W, Li Y. The antimicrobial potential of 14 natural herbal dentrifices: Results of an in vitro diffusion method study. J Am Dent Assoc 2004; 135(5):1133- 1141.

18. Aggarwal BB, Sundaram C, Malani N, Ichikawa H: Curcumin: The Indian solid gold. Adv Exp Med Biol 2007; 595:1-75.

19. Singh KN, Lal B, Note on traditional uses of Khair (Acacia catechu Wild.) by inhabitants of shivalik range of western Himalaya, Ethnobotanical Leaflets 2006; 10:109-112.

20. Qadry J S, Shah's and Qadry's Pharmacognosy, 12th edition, B.S Shah Prakashan, Ahmedabad 2008; 302-303.

21. Ernst $E$, Adverse effects of herbal drugs in dermatology. British J Derm 2000; 143:923-929.

22. Rai Y. Holy Basil: Tulsi (A Herb), Navneet Publications India Ltd., 2002.

23. Sen $P$, Therapeutic potential of Tulsi: from experience to facts. Drugs News and views 1993; 1:15-21.
24. Narayana KR, Reddy MS, Chaluvadi MR, Krishna DR. Bioflavanoids: classification, pharmacology, biochemical effects and therapeutic potential. Indian J ournal of Pharmacol 2001; 33:2-16.

25. Abdelrahim SI, Almagboul AZ, Omer MEA Elegami. Antimicrobial activity of Psidium guajava. Fitoterapia 2002; 73(778):713-715

26. Gnan SO, Demello MT. Inhibition of Staphylococcus aureus by aqueous goiaba extracts. J Ethnopharm 1999; 68:103108.

27. Sofrata A, Santangelo EM, Muhammad Azeem M, Karlson AK, Gustafsson A, Putsep K. Benzyl isothiocyanate, a major component from the roots of salvadora persica is highly active against gramnegative bacteria. PLoS One 2011; 6:23045.

28. Parveen Dahiya, Reet Kamal, RP Luthra, Rahul Mishra, Gaurav Saini. Miswak: A periodontist's perspective. J Ayurveda Integr Med 2012; 3(4):184-187.

29. Gazi M, Saini T, Ashri N, Lambourne A. Meswak chewing stick versus conventional toothbrush as an oral hygieneaid. Clin Prev Dent 1990; 12:19-23.

30. Anonymous. The wealth of I ndia (Raw material) CSIR, I ndia 1950; 11:411-415.

31. Ruchika ghoyal, Meena k Anand. Antibacterial effect of lemon grass oil on oral microorganisms: an in vitro study. J Pharma Scientific Iinnovation 2013; 2(2):41-43.

32. Prevention Methods and Programmes for Oral Health. Report of a WHO Expert Committee Technical Report Series 713. Geneva: WHO; 1984.

33. Nagata $\mathrm{H}$, Inagaki $\mathrm{Y}$, Tanaka $\mathrm{M}$, Miki O Kataoka $\mathrm{K}$, Kuboniwa $\mathrm{M}$, et al. Effect of eucalyptus extract chewing gum on periodontal health: A double-masked, randomized trial. J Periodontol 2008; 79:1378-1385.

34. Nagata $\mathrm{H}$, Inagaki $\mathrm{Y}, \mathrm{Yamamoto} \mathrm{Y}$, Maeda $\mathrm{K}$, Kataoka $\mathrm{K}$, Osawa K, et al. Inhibitory effects of macrocarpals on the biological activity of Porphyromonas gingivalis and other periodontopathic bacteria. Oral Microbiol Immunol 2006; 21:159-163.

35. Evaluation of Antibacterial activity of magnifera indica on anaerobic dental microflora based on in vivo studies, Indian J Pathology Microbiol, 45, 2002, 307-310. 